\title{
Interfaces in Pediatric Gastrointestinal Endoscopy: Who Should Do It?
}

\author{
Thomas Lang \\ Department of Pediatric Gastroenterology, Children's Hospital St. Hedwig, University of Regensburg, Germany
}

\section{Keywords}

Pediatric gastrointestinal endoscopy .

Therapeutic endoscopy · Monitoring · Sedation

\section{Summary}

Background: Gastrointestinal endoscopy is one of the most frequently performed diagnostic and therapeutic procedures in children nowadays. Methods: Since the size of endoscopes has been adapted to pediatric patients, endoscopic procedures are performed almost routinely in pediatric gastrointestinal patients. However, this is an invasive procedure done under deep sedation, and procedure-related or sedation-related complications can occur more easily in pediatric patients. The endoscopist must consider various aspects (e.g., indications and contraindications for endoscopy, monitoring during and after the procedure) to ensure the procedure is performed successfully and safely. Results: In our opinion, pediatric endoscopy should be carried out by pediatric endoscopists at specialized pediatric clinics. In Germany, there are regulatory demands dictating that in order to become a pediatric gastroenterologist, further education is necessary. Experienced centers which offer this education including training programs for pediatric endoscopy can be found on www.gpge.de. Conclusion: Provided these preconditions are adhered to, gastrointestinal endoscopy is a safe and efficient technique with minimal complications even in children and infants.

(C) 2016 S. Karger GmbH, Freiburg

\section{Introduction}

Gastrointestinal endoscopy in children and infants is a widely used diagnostic tool for gastrointestinal disorders. Technically, there are no significant differences in how the procedure is performed in adult and pediatric patients. However, to carry out gastrointestinal endoscopy safely and comfortably in children and infants, certain conditions must be fulfilled. Apart from the characteristic structural preconditions of pediatric endoscopy such as special monitoring equipment and small endoscopes for infants, skilled nurses and physicians responsible for anesthesia or sedation are required. In small infants, endoscopy is indicated for various conditions; thus, endoscopists need to be specially qualified to be able to interpret the diagnostic findings. In this context, it is important to take into account the revised guidelines for pediatric gastrointestinal endoscopy issued by the North American Society of Pediatric Gastroenterology and Nutrition in 2013 [1].

Specific pediatric characteristics relevant to the field of endoscopy will be discussed in the following article including some important guidelines and recommendations for gastrointestinal endoscopy in pediatric patients. In the second part, some typical pediatric indications are presented including endoscopic images taken at our Center of Pediatric Gastroenterology were we perform over 500 endoscopies annually.

\section{Technical and Structural Preconditions}

The basic equipment for pediatric endoscopy consists of a video processor and monitor, a light source, and various endoscopes, as well as washing machines for cleaning the endoscopes. In addition, a digital documentation system is now essential.

Safe endoscopy in infants requires very small endoscopes with an outer diameter of 5-6 $\mathrm{mm}$, which are available from several manufacturers [2]. It goes without saying that equipment such as 

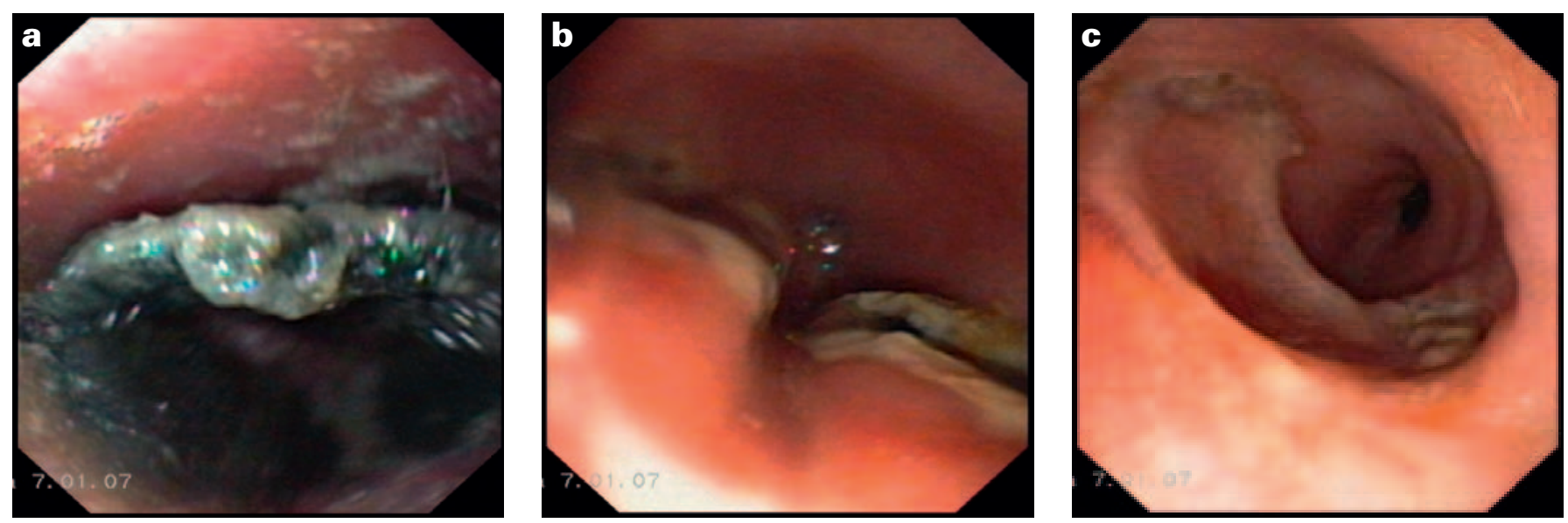

Fig. 1. 2.5-year-old boy, ingestion of a coin battery $4 \mathrm{~h}$ before endoscopy. a Coin battery $(3 \mathrm{~V})$ in the upper narrowing of the esophagus. b Necrotic defects caused by electric current flow 3 days later. c 14 days after ingestion semicircular strictures can be seen. From [11]; printed with kind permission ๑ Georg Thieme Verlag KG.

biopsy forceps, foreign body forceps, polypectomy snares, and sclerotherapy needles suitable for small endoscopes is needed. Often, pediatric gastroenterologists are able to use the equipment of an adult endoscopy unit, thereby saving costs.

An invasive procedure such as endoscopy may provoke an emergency state; hence, intensive monitoring of pediatric patients is essential. Continuous monitoring of oxygen saturation and heart rate (pulse oximeter with pediatric sensors, electrocardiogram) and intermittent blood pressure measurement are absolutely essential. The endoscopy suite must be equipped with pressurized $100 \%$ oxygen and additional suction outlets or a mobile suction unit.

In almost all cases, gastrointestinal endoscopy in infants has to be done under deep sedation or general anesthesia, and for the case that complications arise, it must be possible to react immediately. An emergency trolley completely equipped for cardiopulmonary resuscitation (including different sized masks, instruments for airway intubation, and drugs) should always be on standby.

In our clinic, $90 \%$ of all endoscopies are done under deep sedation (propofol in combination with an opiate). In critically ill infants or with therapeutic endoscopies, general anesthesia is sometimes necessary [3]. It is mandatory that deep sedation of infants is carried out by skilled personnel such as pediatric anesthesiologists (as is done in our department) or pediatric intensive care specialists.

The endoscopist as well as the assisting staff have to be well trained in endoscopy in small infants. It is absolutely forbidden that the pediatric endoscopist be simultaneously responsible for sedation, necessitating the presence of a second skilled person during the procedure [4].

Due to the need for urgent intervention in the case of complications, endoscopic procedures such as dilation of strictures or polypectomy should be carried out in a pediatric clinic with a pediatric surgery department.
Fig. 2. 10-month-old boy several weeks after ingestion of a $3 \mathrm{~V}$ coin battery with perforation. A big tracheoesophageal fistula had formed which needed surgical intervention. From [11]; printed with kind permission () Georg Thieme Verlag KG.

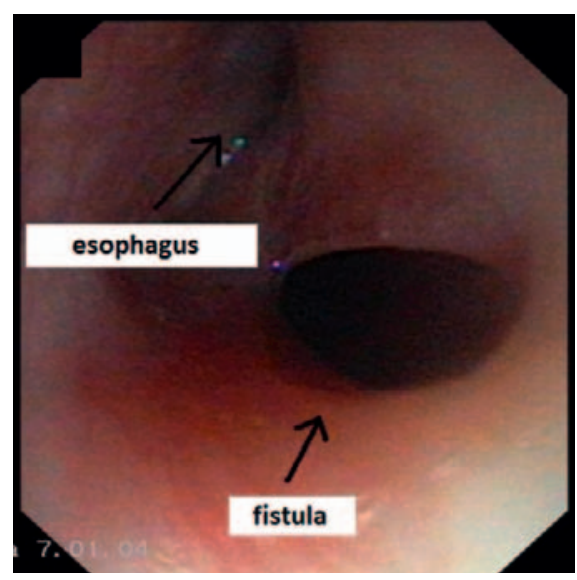

\section{Pediatric Indications for Gastrointestinal Endoscopy}

Patient preparation, special indications or contraindications, and risks and complications related to the procedure are among the factors to be considered before performing endoscopy in small infants. In the following paragraphs, examples of pediatric indications are presented together with endoscopic images from our clinic.

One typical indication for an urgent endoscopy in infants is the ingestion of a foreign body (usually coins, batteries, hair clips, or toy parts). Most affected children are between 1 and 3 years of age; however, ingestion can occur even in the first year of life. A foreign body in the esophagus is an absolutely emergency, and the endoscopy has to be done at once whether or not a confirming X-ray is available. Typical symptoms are refusal to swallow, salivation, and sometimes coughing [5].

The large lithium $3 \mathrm{~V}$ coin batteries measuring $2 \mathrm{~cm}$ in diameter are very dangerous for infants because of their higher voltage in contrast to the widespread $1.5 \mathrm{~V}$ coin batteries which are also smaller in diameter [6]. Only $3 \mathrm{~h}$ after ingestion, deep ulcers can be seen on endoscopy (fig. 1), and sometimes perforations into the 
Fig. 3. 2-year-old girl with ingestion of $\mathrm{KMnO}_{4}$. a This led to severe oxidation of the tongue, a lot of crystals can be seen on the mucosa of the esophagus. b Cleaning with brush and forceps revealed almost normal mucosa; endoscopy 2 days later showed normal results. From [11]; printed with kind permission $\odot$ Georg Thieme Verlag KG.
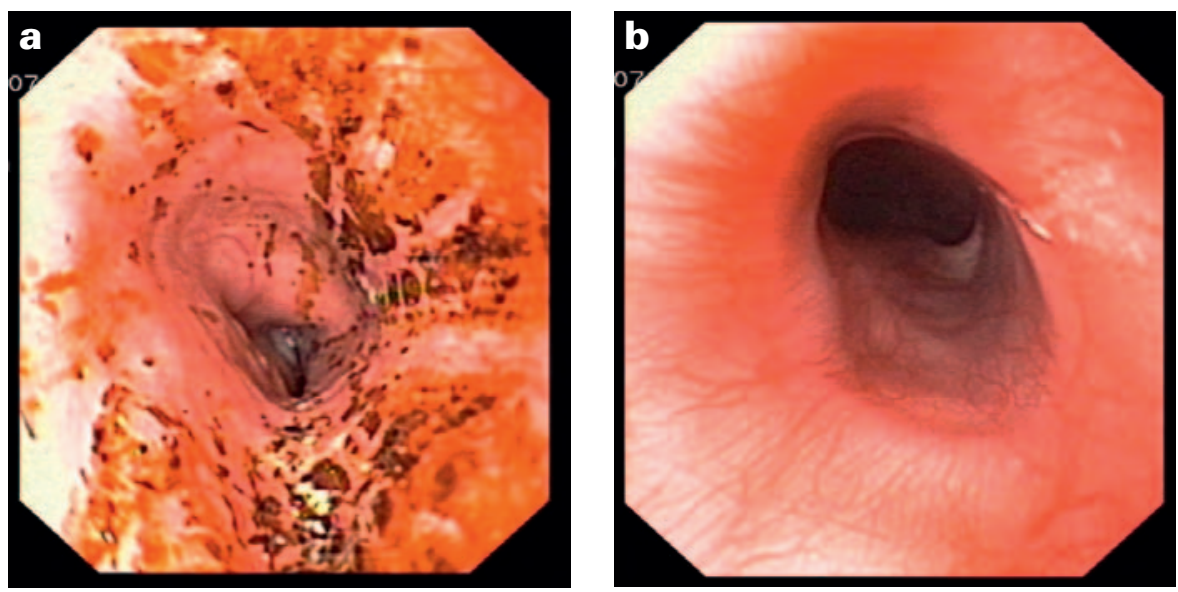

Fig. 4. 4-week-old male infant after esophageal atresia repair. a Marked stricture of the anastomosis of about $1 \mathrm{~mm}$ in diameter, 6 - $\mathrm{mm}$ balloon placed in the stricture. $\mathbf{b}$ After successful dilation with a pressure of $10 \mathrm{bar}$, anastomosis sutures and the guide wire can be seen. From [11]; printed with kind permission $\odot$ Georg Thieme Verlag KG.
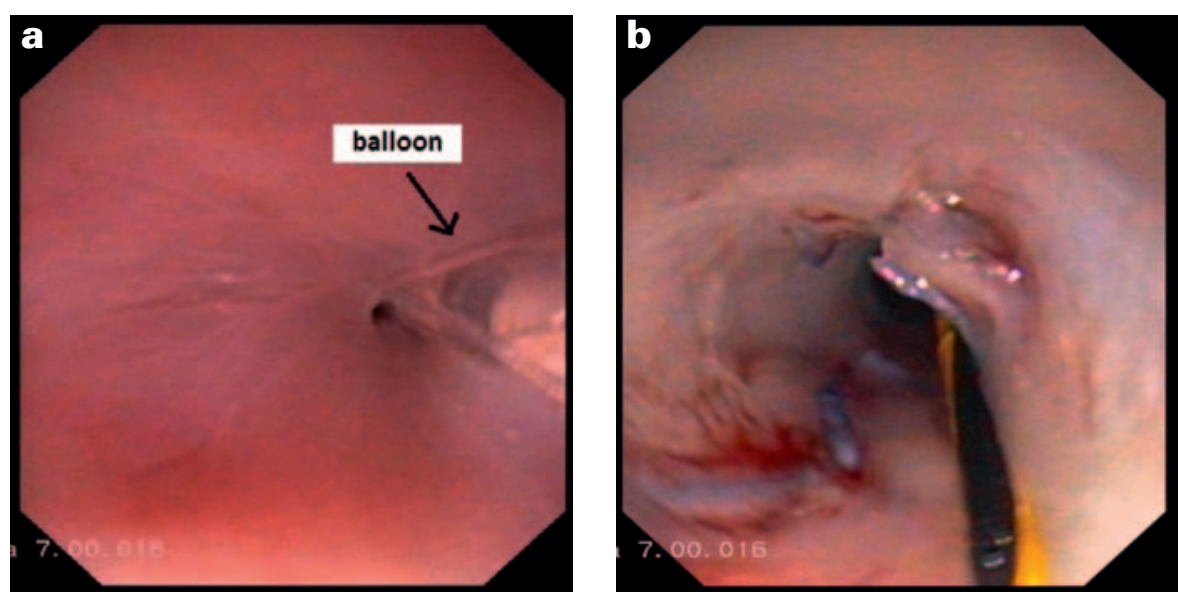

mediastinum or even the tracheobronchial system can occur (fig. 2, tracheoesophageal fistula).

A rare but urgent indication for endoscopy is the ingestion of potassium permanganate $\left(\mathrm{KMnO}_{4}\right)$. The small crystalline particles adhere to the esophageal mucosa where they are capable of aggressively causing perforations. Hence, the endoscopist has to remove each crystal from the mucosa using a forceps or brush (fig. 3a before and fig. $3 \mathrm{~b}$ after removal of $\mathrm{KMnO}_{4}$ ).

Newborns suffering from congenital gastrointestinal malformations commonly undergo surgery. After surgical correction of an esophageal atresia, strictures are a common complication. Endoscopic balloon dilation is a good option for these patients to avoid further surgical interventions (fig. 4). In our institution, we start the dilation with very small balloons (e.g., $6 \mathrm{~mm}$ in diameter) under radiologic control to avoid perforation. In several sessions 4-6 weeks apart, balloons measuring 8 and $10 \mathrm{~mm}$ in diameter are introduced step by step.

Infants with neurological impairment and difficulties swallowing or children who need high-calorie nutrition (e.g., patients with congenital heart failure or cystic fibrosis) often are dependent on tube feeding. In these cases, a percutaneous endoscopic gastrostomy (PEG) is the best choice even in small infants. In all children, even premature infants, we safely use the $14 \mathrm{Ch}$ or $15 \mathrm{Ch}$ PEG. The inner retaining plate of the tube is the limiting factor for doing a
Fig. 5. Normal cholangiogram in a 5-weekold infant. Bile duct atresia can be excluded.

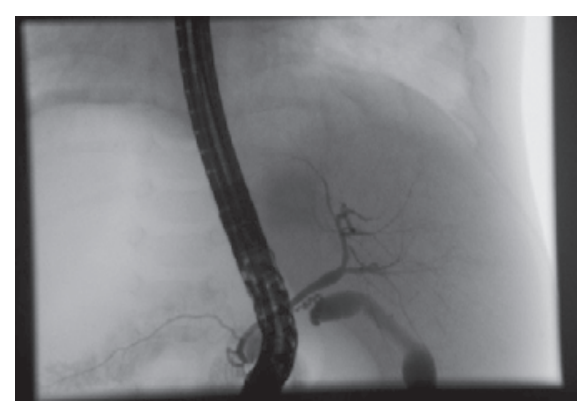

PEG in small infants, as it has the same diameter in the 14Ch and 15Ch PEG as in the 9Ch PEG. Other than that, occlusion of the tube (e.g., with medication) can be avoided by using bigger sizes. Peri-interventional antibiotic therapy is only indicated in immunodeficient children or in patients with ventriculoperitoneal shunts.

Similar to adult patients, endoscopic retrograde cholangiopancreatography (ERCP) with papillotomy is usually the procedure of choice in acute cholestasis in pediatric patients with gallstones. Before a surgical cholecystectomy is planned, several laboratory tests are required to clarify the etiology of the gallstones. Important differences exist compared to adult patients (table 1) [6].

For infants with cholestasis who are only a few weeks old, ERCP is the best diagnostic tool to rule out biliary atresia (fig. 5). In pa- 
tients with a positive cholangiogram, laparotomy and intraoperative cholangiography are unnecessary while otherwise routine steps before a Kasai procedure. ERCP is performed with a special pediatric side-viewing duodenoscope (outer diameter of $7.5 \mathrm{~mm}$ ) in co-

Table 1. Diseases predisposing for gallstones (modified from [7])

\begin{tabular}{ll}
\hline Diseases & Diagnostic tests \\
\hline Cystic fibrosis & $\begin{array}{l}\text { pancreatic elastase in stool } \\
\text { pilocarpine iontophoresis }\end{array}$ \\
\hline Hemolytic diseases & $\begin{array}{l}\text { blood smear, bilirubin (direct/indirect), } \\
\text { osmotic resistance, hemoglobin electro- } \\
\text { phoresis } \\
\text { abdominal ultrasound (hypersplenism) }\end{array}$ \\
\hline Fat metabolism disorders & $\begin{array}{l}\text { triglyceride and cholesterol in serum, } \\
\text { lipid electrophoresis }\end{array}$ \\
\hline Glucose-6-phosphate & glucose-6-phosphate dehydrogenase \\
\hline Inflammatrogenase deficiency bowel disease & $\begin{array}{l}\text { erythrocyte sedimentation rate, C-reactive } \\
\text { protein (CRP), ferritin, calprotectin in } \\
\text { stool, bowel sonography, endoscopy, } \\
\text { magnetic resonance (MR) enteroclysis }\end{array}$ \\
\hline Hyperparathyroidism & $\begin{array}{l}\text { alanine aminotransferase (ALT), aspartate } \\
\text { aminotransferase (AST), glutamate dehy- } \\
\text { drogenase (GLDH), alkaline phosphatase } \\
\text { (ALP), gamma-glutamyl transferase } \\
\text { (GGT), bilirubin (direct/indirect), } \\
\text { abdominal ultrasound, MRCP, ERCP }\end{array}$ \\
\hline Hyperphosphatemia & $\begin{array}{l}\text { CRP, GGT, ALP, AST, ALT, GLDH, } \\
\text { bilirubin (direct/indirect), abdominal } \\
\text { ultrasound, MRCP }\end{array}$ \\
\hline metabolites, X-ray of the left hand \\
\hline Cholangitis & $\begin{array}{l}\text { X-ray of the left hand, abdominal ultra- } \\
\text { sound (nephrocalcinosis) }\end{array}$ \\
\hline $\begin{array}{l}\text { calcium, creatinine in serum and urine, } \\
\text { X-ray of the left hand, abdominal ultra- } \\
\text { sound (nephrocalcinosis) }\end{array}$ \\
\hline
\end{tabular}

Table 2. Functional versus organic causes of abdominal pain operation with an adult endoscopist in a safe pediatric anesthesiological setting.

Recurrent abdominal pain is another indication for diagnostic endoscopy in children. In this setting, the endoscopist must be aware that in over $50 \%$ of cases the chronic abdominal pain has no organic cause. It is very important to only carry out an upper endoscopy in patients with certain symptoms called 'red flags' (table 2). In fact, the pediatric endoscopist must avoid performing unnecessarily high numbers of endoscopies in children.

In pediatric colonoscopy, one typical indication is blood in the stool. The cause of bloody stools depends on age (table 3 ).

Rectal bleeding in small infants is often the result of intolerance to cow's milk protein. Allergic reactions cause lymphofollicular hyperplasia, and the swollen lymphatic tissue itself causes the bloody stools (fig. 6). Affected infants are usually in good condition and appear to be healthy. Colonoscopy is not necessary in typical cases. In formula-fed infants, therapy consists of feeding an extensively hydrolyzed diet or amino acid formula. In breastfed children, the mother has to avoid cow's milk protein in her diet.

Colorectal polyps in toddlers often lead to painless rectal bleeding. Over $90 \%$ of these polyps are left-sided and occur mostly in the rectum. The polyps are removed with polypectomy snares (fig. 7),

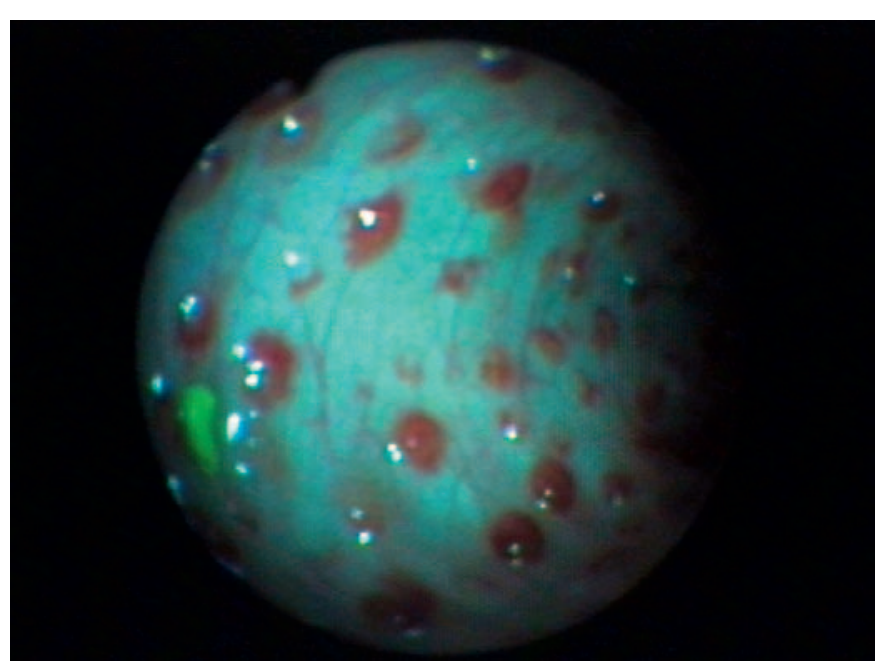

Fig. 6. Allergic reaction in the rectum and sigma to cow's milk protein. From [11]; printed with kind permission @ Georg Thieme Verlag KG.

\begin{tabular}{ll}
\hline Signs typical for functional abdominal pain & Signs typical for organic abdominal pain ('red flags') \\
\hline Diffuse abdominal pain & vomiting \\
Playing not interrupted by pain & hematemesis \\
Undisturbed sleep & hematochezia \\
& weight loss / growth retardation \\
& reflux symptoms \\
& family history (inflammatory bowel disease, Helicobacter pylori) \\
\hline
\end{tabular}

Table 3. Perianal bleeding: typical diseases depending on age (without gastrointestinal infections such as salmonellosis)

\begin{tabular}{ll}
\hline Infants & $\begin{array}{l}\text { allergic colitis; invagination } \\
\text { juvenile polyps; Meckel's diverticulum; rhagades in connection with } \\
\text { constipation }\end{array}$ \\
School-aged children & \begin{tabular}{l} 
inflammatory bowel disease \\
\hline
\end{tabular}
\end{tabular}


Fig. 7. 3-year-old boy with a painless anal bleeding and polyp in the rectum (from [11]; printed with kind permission $\odot$ Georg Thieme Verlag KG). b After hot snare polypectomy, vascular coagulation is complete without signs of bleeding (from [12]; printed with kind permission @ P Primmer Nutricia GmbH).
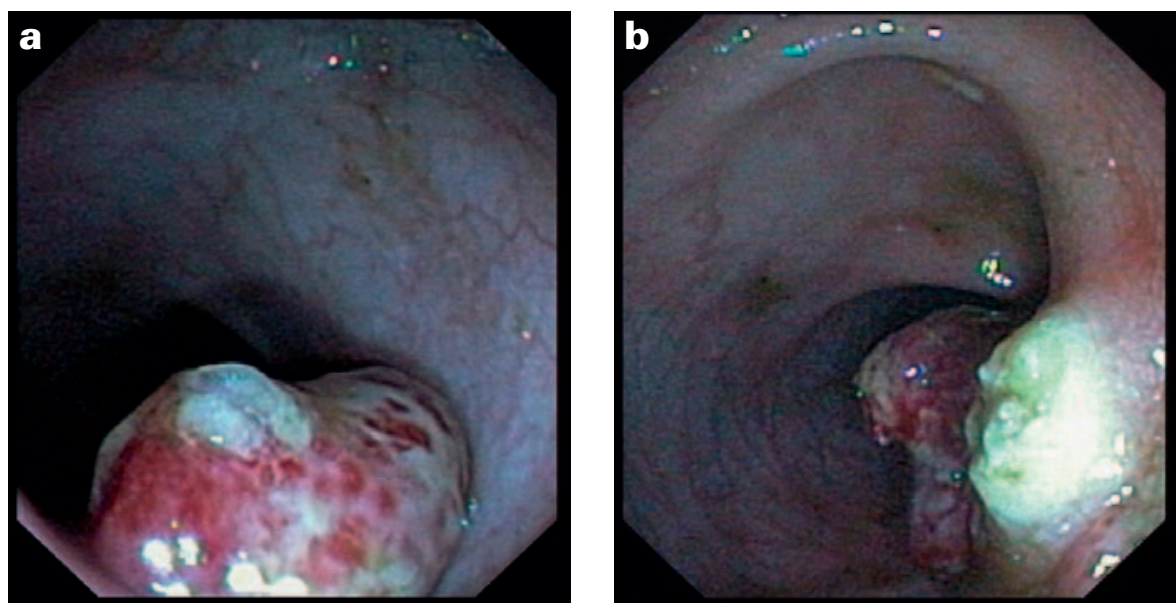

and a histological examination is mandatory. In nearly all cases, the polyps are juvenile polyps without risk for malignancy. Familial polyposis syndromes are rare, and a positive family history is an important warning sign.

\section{Complications in Pediatric Gastrointestinal Endoscopy}

Pediatric gastrointestinal endoscopy is an invasive procedure done under deep sedation or general anesthesia. Thus, complications can occur due to both the anesthesia and the endoscopic procedure.

Anesthesiological complications are rare and mostly occur in small infants or critically ill patients. Therefore, we recommend that a physician trained in endotracheal intubation and cardiopulmonary resuscitation performs the sedation or anesthesia in these patient groups.
Risks in endoscopy include perforations in small infants especially if smaller sized equipment is not available. Bleeding is a rare complication in pediatric patients because of a lower rate of comorbidity and concurrent medication (e.g., anticoagulation).

Pediatric data of complication rates in gastrointestinal endoscopy are scarce, reporting rates between $0.09 \%$ for perforation [8] and $<1 \%$ for all complications $[9,10]$. Data from our Department of Pediatric Endoscopy (3 perforations, no death in 5,022 endoscopies in 15 years) show a rate of severe complications of $0.06 \%$. This is approximately the same rate as found in other series.

\section{Disclosure Statement}

The author declares that he has no conflict of interest to report.

\section{References}

1 Leichtner AM, Gillis LA, Gupta S, Heubi J, Kay M Narkewicz MR, Rider EA, Rufo PA, Sferra TJ, Teitelbaum J; NASPGHAN Training Committee; North American Society for Pediatric Gastroenterology: NASPGHAN guidelines for training in pediatric gastroenterology. J Pediatr Gastroenterol Nutr 2013; $56: \mathrm{S} 1-\mathrm{S} 38$.

2 Volonaki E, Sebire NJ, Borrelli O, Lindley KJ, Elawad M, Thapar N, Shah N: Gastrointestinal endoscopy and mucosal biopsy in the first year of life: indications and outcome. J Pediatr Gastroenterol Nutr 2012;55:62-65.

3 Van Beek EJAH, Leroy PLJM: Safe and effective procedural sedation for gastrointestinal endoscopy in children. J Pediatr Gastroenterol Nutr 2012;54:171-185.
4 Riphaus A, Wehrmann T, Hausmann J, Weber B, von Delius S, Jung M, Tonner P, Arnold J, Behrens A, Beilenhoff U, Bitter H, Domagk D, In der Smitten S, Kallinowski B, Meining A, Schaible A, Schilling D, Seifert H, Wappler F, Kopp I: Update S3-Leitlinie 'Sedierung in der gastrointestinalen Endoskopie' 2014. Z Gastroenterol 2015;53:802-842.

5 Behrens R: Ingestion of foreign bodies in the gastrointestinal tract of children and adolescents. HNO 2012; 60:781-787.

6 Geis T, Lang T: Nächtliches Erbrechen und Schiefhals. Monatsschr Kinderheilk 2008;156:1161-1163.

7 Knoppke B, Schneble F, Melter M: Cholelithiasis im Kindes- und Jugendalter. Pädiat Prax 2008;72:639653.
8 Iqbal CW, Askegard-Giesmann JR, Pham TH, Ishitan MB, Moir CR: Pediatric endoscopic injuries: incidence, management, and outcomes. J Pediatr Surg 2008;43: 911-915.

9 Rothbaum RJ: Complications of pediatric endoscopy. Gastrointest Endosc Clin N Am 1996;6:445-459.

10 Thakkar K, El-Serag HB, Mattek N, Gilger MA: Complications of pediatric EGD: a 4-year experience in PEDS-CORI. Gastrointest Endosc 2007;65:213-221.

11 Lang T: Endoskopie bei Kindern. Gastroenterologie up2date 2013;9:209-226.

12 Behrens R: Endoskopie in der pädiatrischen Gastroenterologie - Lehrbuch und Atlas. Achern, Pfrimmer Nutricia, 2010. 